\title{
Changes in Opioid Prescribing for Chronic Pain in Washington State
}

\author{
Gary M. Franklin, MD, MPH, Deborah Fulton-Kehoe, PhD, Judith A. Turner, PhD, \\ Mark D. Sullivan, MD, PhD, and Thomas M. Wickizer, PhD
}

Purpose: To conduct a survey of primary care physicians and advanced registered nurse practitioners (ARNPs) in Washington State (WA) focused on changes in practice patterns and use of support tools in the prescription of opioids for the treatment of chronic noncancer pain (CNCP).

Methods: A convenience sample of primary care providers in WA was obtained from diverse geographic regions and health care organizations. The web-based anonymous survey was conducted in March-August 2011.

Results: Among 856 provider respondents, 623 reported treating patients with CNCP and served as the analysis sample. Most providers (72\%) reported concern about opioid overdose, addiction, dependence, or diversion. Only $25 \%$ indicated concern about regulatory scrutiny. Only a small proportion of providers overall (3.3\%) reported that they had stopped prescribing opioids for CNCP, but twice as many ARNPs (5.8\%) as physicians (MDs and osteopaths) $\mathbf{( 2 . 1 \% )}$ reported this. A greater proportion of physicians (70.9\%) than ARNPs (40.1\%) reported familiarity with the Washington State opioid dosing guidelines. Physicians in a large health plan with substantial infrastructure support reported less concern about opioids compared with providers in other settings. Of providers in Spokane (the largest city in Eastern Washington), $45 \%$ reported very low capacity to access pain specialty consultation. The vast majority of providers reported a need to access more efficient, innovative means of support and education related to treating patients with $\mathrm{CNCP}$, such as telemedicine consultation.

Conclusions: Overall, prescribing providers in WA reported ongoing concerns regarding opioid use for CNCP, but those affiliated with a health care organization with opioid prescribing guidelines and access to pain consultation were less likely to report being concerned about opioid-related problems or to have discontinued prescribing opioids. (J Am Board Fam Med 2013;26:394-400.)

Keywords: Chronic Pain, Nurse Practitioners, Opioids, Physicians, Primary Health Care

A public health epidemic of morbidity and mortality related to prescribed opioids has engulfed the United States over the past decade, leaving in its wake approximately 15,000 deaths per year. ${ }^{1}$ More citizens in the United States have died since 1999 from unintentional overdoses of prescription opi-

This article was externally peer reviewed.

Submitted 4 October 2012; revised 9 January 2013; accepted 19 January 2013.

From the Departments of Environmental and Occupational Health Sciences (GMF, DF-K) and Health Services (GMF), University of Washington School of Public Health and Community Medicine, Seattle; the Washington State Department of Labor and Industries, Olympia (GMF); the Departments of Neurology (GMF), Psychiatry and Behavioral Sciences (JAT), and Rehabilitation Medicine (JAT), University of Washington School of Medicine, Seattle; and the Division of Health Services Management and Policy, College of Public Health, Ohio State University, Columbus, $\mathrm{OH}(\mathrm{TMW})$. oids than died in the Vietnam War. ${ }^{2}$ Morbidity and mortality are increased in patients prescribed high daily doses of opioids (ie, $>100$ to $120 \mathrm{mg}$ /day morphine-equivalent dose $[\mathrm{MED}]) \cdot{ }^{3-5}$ Although the vast majority of opioid use is short term, recent data suggest that the majority of patients receiving at least 3 months of continuous opioids continue to take opioids at least 2 years later. ${ }^{6}$ Patients taking high doses and showing signs of opioid misuse are the most likely to proceed to years of use. ${ }^{6}$ These

Funding: Funding was provided by the Centers for Disease Control and Prevention, National Center for Injury Prevention and Control (grant no. 5R21CE001850-02).

Conflict of interest: none declared.

Corresponding author: Gary M. Franklin, MD, MPH, 130 Nickerson, Suite 212, Seattle, WA 98109 (E-mail: meddir@ uw.edu) 
data suggest that long-term opioid therapy may be a self-perpetuating or even lifelong therapy that may have a significant adverse financial effect on state Medicaid and workers' compensation systems. ${ }^{7}$ In response to these serious problems, public agencies in the state of Washington (WA) implemented in 2007 the first opioid dosing guideline in the United States, ${ }^{8}$; in 2010 the state passed the first new laws repealing earlier permissive laws, ${ }^{9}$ and implemented regulations ${ }^{10}$ reflective of widely agreed upon best practices for the safe and effective prescription of opioids for chronic noncancer pain (CNCP).

The principal prescribers of opioids for adults with CNCP are primary care providers. These providers-prominently MDs, osteopaths, and, in some states, advanced practice nurses-are in a particularly difficult position, often facing patients with complex pain-related problems and demands. In a survey of WA primary care physicians in early 2009 , the majority of providers reported serious concerns about the development of dependence, addiction, or diversion in their patients with CNCP who were treated with opioids. ${ }^{11}$ Moreover, up to a third of primary care physicians report having experienced severe adverse events, including death, among their patients with CNCP who were treated with opioids. ${ }^{12,13}$ At the same time, one third of WA primary care physicians report difficulty accessing pain consultation to assist in caring for these patients. ${ }^{11}$ These converging circumstances may contribute to the reluctance of primary care providers to initiate opioid therapy in patients with $\mathrm{CNCP}$ or to accept new patients into their practices who are already receiving chronic opioid therapy. ${ }^{12}$ Medical students report that treating complex patients with CNCP and opioids is a reason for them not to enter a primary care field. ${ }^{14}$

To better understand current practice patterns related to opioid prescribing for patients with $\mathrm{CNCP}$ in the rapidly changing policy and regulatory landscape in WA, we conducted a survey of primary care prescribers in the state, including nurse practitioners. In particular, we sought to examine (1) changes in physician practice patterns regarding opioid use for CNCP compared with an earlier survey, 2) differences in practice patterns between advanced registered nurse practitioners (ARNPs) and physicians, and 3) differences be- tween prescribers across regions and health systems likely to have disparities in resource support. In our survey, we paid particular attention not just to identifying recognized problems, but also to identifying potential solutions to the current crisis.

\section{Methods}

\section{Study Design and Survey Development}

The current survey was adapted from a prior survey ${ }^{11}$ of primary care physicians $(\mathrm{N}=655)$ conducted in WA from October through December 2009. We revised the 21 items used in the prior survey ${ }^{11}$ and added questions assessing other areas. The final survey consisted of 39 items and took 15 minutes on average to complete. In this survey, we focused largely on how practice patterns may have changed since implementation of the WA Opioid Dosing Guideline in 2007. ${ }^{8}$ As an example of question format, we asked, "Has the frequency of your opioid prescribing for chronic, noncancer pain changed over the past 3 years?" Response choices were (1) "Yes, I prescribe opioids to more of my chronic pain patients now"; (2) "Yes, I prescribe opioids to fewer of my chronic pain patients now"; (3) "Yes, I stopped prescribing opioids"; (4) "I have not prescribed opioids in the past 3 years"; and (5) "There has been no change in the number of chronic pain patients for whom I prescribe opioids."

We approached numerous organizations and asked either clinical pain specialists/leaders or administrative personnel in those organizations to assist in disseminating the survey. Organizations that agreed to participate included the Washington State Medical Association (by sending out a link in their monthly newsletter); Group Health $(\mathrm{GH})$, a large integrated health plan serving more than 400,000 members in WA (via listserv E-mail distribution by a pain specialist/leader); the Everett Clinic, a large multispecialty clinic in an urban area north of Seattle (via listserv E-mail distribution by a pain specialist/leader); the Washington Academy of Family Practice (via listserv E-mail distribution by administrative personnel); and the Spokane County Medical Society (via direct mail, E-mail, and web/newsletter notification by administrative personnel). The Spokane County Medical Society was added at their request because of perceived concerns regarding opioid use in the county. In addition, a current mailing list of actively practicing 
ARNPs was accessed through the WA Department of Health, and invitations were mailed from our research office to ARNPs regarding potential participation. Once distributed in each organization or group, the survey was available for up to 120 days. Like the earlier survey, our adapted survey was anonymous and web-based, using Survey Monkey (http://www.surveymonkey.com/). The current survey was conducted from March through August 2011. The project was approved by the University of Washington Human Subjects Review Committee.

\section{Statistical Analysis}

The analysis sample consisted of survey respondents who said that they treated patients with CNCP. We used descriptive statistics to characterize the sample and survey responses. We used $\chi^{2}$ tests to compare responses of different types of providers and providers in different settings. In particular, we compared responses of physicians and ARNPs. We also compared responses of providers in Spokane, the largest city in Eastern WA (county population of 451,000) with those of providers in other regions of the state. Finally, we compared responses of providers affiliated with $\mathrm{GH}$, a nonprofit health care system in WA that in 2010 implemented a multifaceted risk mitigation initiative and guideline targeting management of patients receiving long-term opioid therapy. ${ }^{15}$ Statistics were analyzed using 2-tail tests, and we considered statistical significance to be $P<.05$. SPSS version 15.0 (SPSS, Inc., Chicago, IL) was used to conduct the analyses.

\section{Results}

A total of 856 providers completed the survey. Response rates varied somewhat across the organizations: Group Health, 10.8\% (63 of 584 providers on the E-mail distribution list); Washington Academy of Family Practice, 6.3\% (169 of 2700 providers on the E-mail distribution list); and ARNPs, $8.5 \%$ (425 of 5000 who were mailed invitations to participate). Of these respondents, 623 said that they treated patients with CNCP; the respondents are the focus of this report. Among these respondents, 253 self-identified as an MD (40.6\%), 243 as an ARNP (39\%), 32 as an osteopath (5.1\%), and 16 as a physician assistant (2.6\%). Respondents with missing data for provider type $(\mathrm{n}=79)$ were ex- cluded from analyses by provider type. For analyses related to physicians, MDs and osteopaths are combined.

Overall, physician responses were similar to the responses in the prior survey, ${ }^{11}$ with the exception that $71 \%$ of physicians in the current survey reported that they had read and/or applied the WA Opioid Dosing Guideline ${ }^{8}$ compared with $62 \%$ in $2009(P=.01)$. Compared with the 2009 survey, the current survey sample included a greater proportion of female providers $(62.5 \%$ vs. $40 \%)$ and a smaller proportion of MDs ( $41 \%$ vs. $88 \%$ ).

Table 1 summarizes the providers' reported opioid prescribing practices. Physicians were more likely than ARNPs to report prescribing opioids to $\geq 50 \%$ of their patients with CNCP $(39.8 \%$ of physicians vs. $21.7 \%$ of ARNPs; $P<.01)$. Fewer $\mathrm{GH}$ providers $(18.8 \%)$ than non-GH providers (42.7\%) reported prescribing opioids to $\geq 50 \%$ of their patients with $\mathrm{CNCP}(P=.008)$. Although $44.4 \%$ of respondents overall reported prescribing opioids to fewer patients with CNCP than in the past, the majority of both GH (60.4\%) and Spokane providers $(63 \%)$ reported this. More than twice as many ARNPs (5.8\%) as physicians (2.1\%) reported having stopped prescribing opioids altogether $(P=.03)$. No $\mathrm{GH}$ providers reported that they stopped prescribing opioids. A majority of both GH (57.4\%) and Spokane (58.9\%) providers reported prescribing higher doses of opioids less often. A majority of providers $(72.3 \%$ overall; $73.1 \%$ of physicians) reported being very concerned about overdose, addiction, dependence, or diversion. In the 2009 survey, 54\% of physicians reported those concerns. In the current survey, a somewhat smaller proportion of $\mathrm{GH}$ providers $(61.7 \%)$ reported being very concerned about those opioid-related problems compared with non-GH providers $(73.2 \% ; P=.09)$. A minority of all survey respondents who saw patients with CNCP (25.3\%) indicated that they were very concerned about regulatory scrutiny. Only $12.8 \%$ of $\mathrm{GH}$ providers were so concerned, compared with $26.4 \%$ of non-GH providers $(P=.07)$.

Table 2 provides information about the use of the WA Opioid Dosing Guideline and other resources. Compared with physicians, fewer ARNPs had read and/or applied the guideline (40.1\% of ARNPs vs. $70.9 \%$ of physicians; $P<.01)$. The majority of providers $(87 \%)$ felt that the $120 \mathrm{mg} /$ day MED yellow 
Table 1. Opioid Prescribing Practices of 623 Primary Care Physician and Advanced Registered Nurse Practitioner (ARNP) Survey Respondents, Overall and by Physician, ARNPs, and Two Large Practice Site Subgroups*

\begin{tabular}{|c|c|c|c|c|c|}
\hline & Overall (623) & Physicians & ARNPs & Spokane & $\begin{array}{l}\text { Group } \\
\text { Health }\end{array}$ \\
\hline $\begin{array}{l}\text { Prescribes opioids to } \geq 50 \% \text { of patients } \\
\text { with CNCP }\end{array}$ & $186 / 610(30.5)$ & $113 / 284(39.8)$ & $52 / 240(21.7)$ & $25 / 75(33.3)$ & $9 / 48(18.8)$ \\
\hline \multicolumn{6}{|l|}{ Now prescribes opioids to: } \\
\hline More CNCP patients & $63 / 601(10.5)$ & $29 / 284(10.2)$ & $27 / 240(11.3)$ & $3 / 73(4.1)$ & $2 / 48(4.2)$ \\
\hline Fewer CNCP patients & $267 / 601(44.4)$ & $129 / 284(45.4)$ & $103 / 240(42.9)$ & $46 / 73(63.0)$ & $29 / 48(60.4)$ \\
\hline Stopped prescribing & $20 / 601(3.3)$ & $6 / 284(2.1)$ & $14 / 240(5.8)$ & $2 / 73(2.7)$ & $0 / 48(0)$ \\
\hline \multicolumn{6}{|l|}{ Now prescribes: } \\
\hline Higher doses more often & $34 / 594(5.7)$ & $17 / 282(6.0)$ & $12 / 238(5.0)$ & $1 / 73(1.4)$ & $1 / 47(2.1)$ \\
\hline Higher doses less often & $277 / 594(46.6)$ & $142 / 282(50.4)$ & $97 / 238(40.8)$ & $43 / 73(58.9)$ & $27 / 47(57.4)$ \\
\hline No Change & $262 / 594(44.1)$ & $117 / 282(41.5)$ & $116 / 238(48.7)$ & $26 / 73(35.6)$ & $18 / 47(38.3)$ \\
\hline \multicolumn{6}{|l|}{$\begin{array}{l}\text { When prescribing opioids, how concerned } \\
\text { are you about (\% very concerned): }\end{array}$} \\
\hline $\begin{array}{l}\text { Overdose or addiction or dependence } \\
\text { or diversion }\end{array}$ & $425 / 588(72.3)$ & $207 / 283(73.1)$ & $169 / 236(71.6)$ & $56 / 73(76.7)$ & $29 / 47(61.7)$ \\
\hline Regulatory scrutiny & $149 / 588(25.3)$ & $79 / 283(27.9)$ & $54 / 235(23.0)$ & $21 / 72(29.2)$ & $6 / 47(12.8)$ \\
\hline
\end{tabular}

Values are $\mathrm{n} / \mathrm{N}(\%)$.

*There were 623 respondents who said that they treated patients with chronic noncancer pain (CNCP), but the sample size for each question differed because of missing data and skip patterns. The physician, ARNP, Spokane, and Group Health categories are subgroups of the overall group and may overlap.

flag dose in the guideline was reasonable $(71 \%)$ or too high (16\%). More physicians compared with ARNPs reported having access to opioid prescribing policies and tools in their clinics $(68.1 \%$ vs. $48.5 \% ; P<.01)$ and electronic prescription records linked to electronic health records $(84.1 \%$ vs. $62.5 \% ; P<.01)$ that could assist in supporting appropriate opioid use. Spokane providers were the most likely to report "never or almost never" successfully obtaining a pain consultation compared with non-Spokane providers ( $42.5 \%$ vs. $12.8 \% ; P<.01$ ). Only $3.3 \%$ of GH providers reported such difficulty compared with $16.7 \%$ of non-GH providers $(P<.01)$.

The great majority of all groups thought that specific innovative methods of consultation or assistance, such as telephone or video consultation with experts, would be helpful. Nearly $90 \%$ reported that webbased continuing medical education training would be useful. Only a minority of providers overall $(17.6 \%)$ reported participating in collaborative therapy arrangements with pharmacists, but $47.7 \%$ of $\mathrm{GH}$ providers reported this capacity versus $14.9 \%$ of non-GH providers $(P<.01)$.

\section{Discussion}

Primary care providers in the United States find themselves at an important crossroads concerning opioid therapy for CNCP. For more than a decade, pain experts and organized medicine called for more adequate treatment of pain with opioids, which increased prescribing by physicians and other providers who treated patients with $\mathrm{CNCP} .{ }^{16}$ Rates of use and daily doses of the most powerful schedule II opioids then rose dramatically. ${ }^{17}$ These increased rates of use- especially increased rates of high-dose use-have contributed to the public health epidemic of overdose morbidity and mortality that has occurred over the past decade..$^{3-5}$

In 2007, WA was the first state or jurisdiction to implement specific dosing guidance for opioids in the treatment of CNCP. ${ }^{8}$ It was also the first state to repeal the "Intractable Pain" laws that had legalized long-term opioid therapy without a dosing ceiling and to implement new laws and regulations reflecting generally agreed upon best practices. ${ }^{9,10}$ In a 2009 survey primary care physicians in WA reported that they rarely used most of these best practices and that they thought that more guidance and community resources, including dosing guidance, was needed. ${ }^{11}$ WA agencies and our collaborating clinical and academic advisors responded with an updated Opioid Dosing Guideline in June 2010, which contained tools needed to implement most of the best practices. ${ }^{8}$ 
Table 2. Availability/Use of Guidelines, Tools, and Consultation, by Group*

\begin{tabular}{|c|c|c|c|c|}
\hline & Overall $(\mathrm{n}=623)$ & Physicians & Spokane & Group Health \\
\hline Read and/or applied guideline & $309 / 562(55)$ & $200 / 282(70.9) 95 / 237(40.1)$ & $33 / 65(50.8)$ & $27 / 45(60.0)$ \\
\hline $\begin{array}{l}\text { Yellow flag dose }(120 \mathrm{mg} / \text { day morphine } \\
\text { equivalents) reasonable or too high }\end{array}$ & $489 / 561(87.2)$ & $241 / 283(85.2) 211 / 237(89.0)$ & $58 / 65(89.2)$ & $42 / 46(91.3)$ \\
\hline \multicolumn{5}{|l|}{ Tools available in clinic } \\
\hline $\begin{array}{l}\text { Policy, guideline, or algorithm for prescribing } \\
\text { opioids for CNCP }\end{array}$ & $344 / 592(58.1)$ & $194 / 285(68.1) 116 / 239(48.5)$ & $39 / 72(54.2)$ & $42 / 47(89.4)$ \\
\hline Electronic prescription record linked to EMR & $440 / 590(74.6)$ & $238 / 283(84.1) 150 / 240(62.5)$ & $57 / 71(80.3)$ & $45 / 46(97.8)$ \\
\hline $\begin{array}{l}\text { Of those who tried to obtain a pain management } \\
\text { consultation, percentage never or almost } \\
\text { never successful }\end{array}$ & $64 / 408(15.7)$ & $34 / 219(15.5) 29 / 175(16.6)$ & $17 / 40(42.5)$ & $1 / 30(3.3)$ \\
\hline \multicolumn{5}{|l|}{$\begin{array}{l}\text { How helpful would you find each of the following } \\
\text { in managing your patients with CNCP? (\% } \\
\text { somewhat or very helpful) }\end{array}$} \\
\hline Telephone consultation with experts & $445 / 532(83.6)$ & $219 / 282(77.7) 212 / 234(90.6)$ & 49/61 (80.3) & $39 / 44(88.6)$ \\
\hline Telemedicine or web-based tool & $360 / 532(67.7)$ & $169 / 281(60.1) 178 / 235(75.7)$ & $44 / 61(72.1)$ & $28 / 43(65.1)$ \\
\hline Web-based CME training & $466 / 531(87.8)$ & $234 / 279(83.9) 218 / 235(92.8)$ & $49 / 61(80.3)$ & $40 / 43(93.0)$ \\
\hline Patient decision aids & $468 / 533(87.8)$ & $240 / 280(85.7) 213 / 237(89.9)$ & $54 / 60(90.0)$ & $37 / 43(86.0)$ \\
\hline $\begin{array}{l}\text { Advanced training that would provide a } \\
\text { certificate of special competence in treatment } \\
\text { of CNCP }\end{array}$ & $420 / 531(79.1)$ & $195 / 278(70.1) 209 / 236(88.6)$ & $41 / 60(68.3)$ & $34 / 43(79.1)$ \\
\hline Prescription monitoring program & $479 / 534(89.7)$ & $255 / 280(91.1) 207 / 237(87.3)$ & $57 / 61(93.4)$ & $42 / 44(95.5)$ \\
\hline $\begin{array}{l}\text { Collaborative drug therapy agreement with } \\
\text { pharmacists to prescribe or manage patients } \\
\text { taking opioids (\% yes) }\end{array}$ & $95 / 539(17.6)$ & $96 / 284(33.8) 37 / 238(15.5)$ & $8 / 62(12.9)$ & $21 / 44(47.7)$ \\
\hline
\end{tabular}

Values are $\mathrm{n} / \mathrm{N}(\%)$

*There were 623 respondents who said that they treated patients with chronic noncancer pain (CNCP), but the sample size for each question differed because of missing data and skip patterns. The physician, advanced registered nurse practitioner (ARNP), Spokane, and Group Health categories are subgroups of the overall group and may overlap.

CME, continuing medical education; EMR, electronic medical record; Q24f.

When the WA Opioid Dosing Guideline was first published online in April 2007, it received strong negative feedback from professional pain organizations and patient advocacy groups and a lawsuit was filed but was subsequently overturned. However, in the 2009 survey of WA primary care physicians, $86 \%$ reported that a yellow flag dose of $120 \mathrm{mg} /$ day MED was reasonable $(75 \%)$ or too high $(11 \%)$, which is similar to the results of the current survey (71\% and $16 \%$, respectively). ${ }^{11}$ Of primary care prescribers who responded to the 2009 survey, 54\% were concerned about dependence, addiction, and diversion. In the current survey, an even larger proportion of providers (72\%) reported similar concerns. These concerns are consistent with survey data collected from primary care physicians in low-income clinics in the United States, ${ }^{12}$ Canada, ${ }^{13}$ and Veterans Affairs medical clinics. ${ }^{18}$ Thus, while primary care physicians generally express confidence in their ability to use opioids to treat CNCP,${ }^{12,13}$ potential risks of de- pendence and addiction and lack of community and system resources are significant concerns.

In the current survey, providers in a large WA integrated health plan $(\mathrm{GH})$ that has a long tradition of innovation in chronic care reported fewer concerns regarding opioid prescribing for CNCP. This is likely because of strong institutional support throughout the organization for adoption of best practices regarding opioid prescribing, including a risk mitigation initiative and prescribing guideline targeting patients receiving chronic opioid therapy that was implemented in October 2010. ${ }^{15}$ Although $3.3 \%$ of all providers statewide reported they had stopped prescribing opioids for $\mathrm{CNCP}$, no GH provider in our survey reported doing so. While $16.7 \%$ of non-GH providers and $42.5 \%$ of Spokane providers reported that they "never or almost never" can access a pain consultation, only one GH physician reported such difficulty. When WA passed new opioid laws early in $2010,{ }^{9}$ concern was expressed regarding regulatory 
scrutiny and potential overreach by the government. However, in the current survey, conducted about 1 year after passage of the law, only a minority of WA providers overall (25.3\%) reported being very concerned about regulatory scrutiny. Among providers at $\mathrm{GH}$, only $12.8 \%$ reported such concern. In Spokane, a community with less support for opioid prescribing and chronic pain management best practices, 29.2\% expressed concern.

Although ARNPs may prescribe controlled substances in WA and in most states, ${ }^{19}$ this is the first report of opioid prescribing practices specific to ARNPs. Of the respondents in this survey, 39\% were ARNPs. Overall, in our survey, ARNPs, as compared with physicians, were less likely to report prescribing opioids to the majority of their patients with CNCP, to have read/applied the WA Opioid Dosing Guideline, or to have available opioid policy tools or electronic health records in their clinical setting. Compared with WA physicians, ARNPs were more than twice as likely to have stopped prescribing opioids altogether to their patients with CNCP. The reasons for these differences are not clear.

Limitations of this study include the use of a convenience sample and a low response rate. The 2009 survey focused on acceptance and diffusion of the 2007 Opioid Dosing Guideline, whereas the current survey was expanded to include a focus on changing practices and needed resources. The addition of ARNPs to the survey sample and different methods of accessing respondents resulted in differences between the 2009 survey and the current survey that precluded ability to directly compare results.

Although questions remain concerning the longterm effectiveness of opioid therapy in people with $\mathrm{CNCP}$, there is little question that more community-based resources will be necessary to effectively treat patients with CNCP. In this survey, the great majority of all prescribers reported enthusiasm for the diffusion of tools to help them manage patients with CNCP, including phone consultations with experts, web-based tools, web-based continuing medical education, and other advanced training, patient decision aids, and computerized programs to monitor prescription drugs. The current results also suggest a pressing need to increase capacity in the majority of communities that do not have the substantial resources required to effectively address chronic pain. ${ }^{16}$
We have begun to develop such capacity through payment incentives for best practices and improved care coordination among injured workers in $\mathrm{WA}^{20}$ and by offering more efficient means of consultation, such as the use of video-linked consultations with panels of university-based experts. ${ }^{21}$ The prevention and adequate treatment of chronic pain should be considered in the same conceptual framework offered by leaders of integrated care management for other chronic diseases. ${ }^{22}$ As such, a medical home model to address chronic pain as a community-wide health delivery innovation should be considered. Insurers will be critical in developing incentives for best practices that could be effective alternatives to opioids in preventing and treating chronic pain, such as reducing patient avoidance of fear and promoting patient participation in customary activities, graded exercise, cognitive-behavioral therapy, and multidisciplinary intensive rehabilitation. ${ }^{23}$ In addition, incentivizing balanced, evidence-based provider education on these best practices will be necessary to help ensure their dissemination.

\section{Conclusion}

Opioids have not turned out to be the effective and "not as addicting as we used to believe" treatment that some pain champions and pharmaceutical companies promised, based on no good scientific evidence, in the late $1990 \mathrm{~s} .{ }^{24} \mathrm{We}$ were told that there is no ceiling on dose and that the best way to treat tolerance is to keep increasing dose. We have now learned that dose is highly related to morbidity and mortality ${ }^{3-5}$; implementation of more clear-cut dosing guidance and other best practice tools are needed at this point. ${ }^{8,15}$ Practitioners are clamoring for more guidance and community resources to deal with the multitude of patients now receiving longterm opioid therapy and the many other patients with chronic pain who are not taking opioids. There is a particularly urgent and critical need for research that will generate the information necessary to prevent the next cohort of patients from getting potentially lethal but ineffective doses of opioids and to shed light on effective ways to improve the suffering and function of those who already are dependent on or addicted to opioids and are still in pain. 
We thank Kathleen Egan for survey administration, Rae Wu for data management and analysis, and Laura Black for manuscript preparation.

\section{References}

1. Centers for Disease Control and Prevention (CDC). Vital signs: overdoses of prescription opioid pain relievers-United States, 1999-2008. MMWR Morb Mortal Wkly Rep 2011;60:1487-92.

2. Warner M, Chen LH, Makuc DM, Anderson RN, Minino AM. Drug poisoning deaths in the United States, 1980-2008. NCHS Data Brief 2011;(81):1-8.

3. Dunn KM, Saunders KW, Rutter CM, et al. Opioid prescriptions for chronic pain and overdose: a cohort study. Ann Intern Med 2010;152:85-92.

4. Bohnert ASB, M V, Bair MJ, et al. Association between opioid prescribing patterns and opioid overdose-related deaths. JAMA 2011;305:1315-21.

5. Gomes T, Mamdani MM, Dhalla IA, Paterson JM, Juurlink DN. Opioid dose and drug-related mortality in patients with nonmalignant pain. Arch Intern Med 2011;171:686-91.

6. Martin BC, Fan MY, Edlund MJ, Devries A, Braden JB, Sullivan MD. Long-term chronic opioid therapy discontinuation rates from the TROUP study. J Gen Intern Med 2011;26:1450-7.

7. Meier B. Pain pills add cost and delays to job injuries. The New York Times. June 2, 2012. Available from: http://www.nytimes.com/2012/06/ 03/health/painkillers-add-costs-and-delays-to-work place-injuries.html? pagewanted=all. Accessed September 5, 2012.

8. Washington Agency Medical Director's Group. Opioid dosing guideline for chronic noncancer pain. Available from: http://www.agencymeddirectors.wa. gov/opioiddosing.asp. Accessed September 5, 2012.

9. Washington Engrossed Substitute House Bill 2876. an act relating to pain management. March 26, 2010. Available from: http://apps.leg.wa.gov/documents/billdocs/ 2009-10/pdf/bills/session\%20laws/house/2876s.sl.pdf. Accessed September 5, 2012.

10. Washington State Department of Health. Pain management. Adopted rules. Available from: http://www.doh.wa. gov/PublicHealthandHealthcareProviders/Healthcare ProfessionsandFacilities/PainManagement/Adopted Rules.aspx. Accessed September 5, 2012.

11. Morse JS, Stockbridge H, Egan KB, Mai J, Wickizer T, Franklin GM. Primary care survey of the value and effectiveness of the Washington State Opioid Dosing Guideline. J Opioid Manag 2011;7:427-33.

12. Leverence RR, Williams RL, Potter M, et al. Chronic non-cancer pain: a siren for primary care-a report from the PRImary care MultiEthnic Network (PRIME Net). J Am Board Fam Med 2011;24:551-61.

13. Wenghofer F, Wilson L, Kahan M, et al. Survey of Ontario primary care physicians' experiences with opioid prescribing. Can Fam Physician 2011;57: 324-32.

14. Corrigan C, Desnick L, Marshall S, Bentov N, Rosenblatt RA. What can we learn from first-year medical students' perceptions of pain in the primary care setting? Pain Med 2011;12:1216-22.

15. Trescott CE, Beck RM, Seelig MD, Von Korff MR. Group Health's initiative to avert opioid misuse and overdose among patients with chronic noncancer pain. Health Aff (Millwood) 2011;30:1420-4.

16. Committee on Advancing Pain Research, Institute of Medicine. Relieving pain in America: a blueprint for transforming prevention, care, education, and research. Washington, DC: National Academies Press; 2011. Available from: http://www.iom.edu/Reports/2011/ Relieving-Pain-in-America-A-Blueprint-for-Trans forming-Prevention-Care-Education-Research.aspx. Accessed May 15, 2013.

17. Franklin GM, Mai J, Wickizer T, Turner JA, Fulton-Kehoe D, Grant L. Opioid dosing trends and mortality in Washington State workers' compensation, 1996-2002. Am J Ind Med 2005;48:91-9.

18. Dobscha SK, Corson K, Flores JA, Tansill EC, Gerrity MS. Veterans affairs primary care clinicians' attitudes toward chronic pain and correlates of opioid prescribing rates. Pain Med 2008;9:564-71.

19. Nurse practitioner prescriptive authority. Available from: http://nursinglicensemap.com/advancedpractice-nursing/nurse-practitioner/nurse-practitionerprescriptive-authority/. Accessed September 5, 2012.

20. Wickizer TM, Franklin G, Fulton-Kehoe D, et al. Improving quality, preventing disability and reducing costs in workers' compensation healthcare: a population-based intervention study. Med Care 2011;49:1105-11.

21. UW Pain Medicine Patient Care: TelePain. Available from: http://depts.washington.edu/anesth/care/pain/ telepain/index.shtml. Accessed September 5, 2012.

22. Coleman K, Austin BT, Brach C, Wagner EH. Evidence on the chronic care model in the new millennium. Health Aff (Millwood) 2009;28:75-85.

23. Chou R, Qaseem A, Snow V, et al. Diagnosis and treatment of low back pain: a joint clinical practice guideline from the American College of Physicians and the American Pain Society. Ann Intern Med 2007;147:478-91.

24. Meier B. A World of Hurt: Fixing Pain Medicine's Biggest Mistake. New York: New York Times ebook; 2013. 